\title{
Understanding the Challenges of Induction of Lactation and Relactation for Non-Gestating Spanish Mothers
}

Journal of Human Lactation I-9

(c) The Author(s) 2019 Article reuse guidelines: sagepub.com/journals-permissions DOI: $10.1177 / 0890334419852939$ journals.sagepub.com/home/jhl

(S)AGE

\author{
Gemma Cazorla-Ortiz ${ }^{1,2}$, Paola Galbany-Estragués, PhD ${ }^{3,4}$, \\ Noemí Obregón-Gutiérrez, $P D^{1,2}$, and Josefina Goberna-Tricas, PhD $^{5}$
}

\begin{abstract}
Background: Induced lactation and relactation are the processes that enable breastfeeding in non-gestating mothers.

Research aim: The aim of this study was to describe and interpret the challenges faced by mothers who undergo induced breastfeeding and relactation for adopted infants, infants born via surrogacy, and infants born to same-sex female partners.

Methods: A qualitative study was performed using in-depth interviews conducted with Spanish women $(N=9)$ who had decided to undergo induced lactation or relactation. The data were collected between October 2014 and May 2017. The length of the study was due to the difficulty in locating and recruiting the sample. Interviews were transcribed and coded with the ATLAS.ti v.7.5.7 software. We performed a deductive thematic analysis, creating categories based on the interview questions, which we developed on the basis of previous literature about induced lactation and relactation.

Results: Participants described the following challenges: the physical hardships of the process; breastfeeding problems; difficulty with accessing information about induced lactation or relactation; and lack of support from health professionals. Breastfeeding periods lasted from 1.5 months to 4 years. Participants reported that breastfeeding increased the closeness between the mother and child and that this feeling of closeness tended to decrease after breastfeeding cessation.

Conclusion: We offer data and analysis that can improve our understanding of the lived experiences of women undergoing the process of relactation or induced lactation and may help guide intervention strategies to support women in this situation.
\end{abstract}

\section{Keywords}

breastfeeding, induced lactation, qualitative methods, relactation

\section{Background}

Human milk, as the normal food for infants, contains antibodies and a multitude of other immune factors needed for normal growth and development and the long-term protection from numerous chronic illnesses. It also reduces the mother's risk of breast and ovarian cancer, Type 2 diabetes, and postpartum depression (World Health Organization [WHO], 2017). Additionally, Gibbs, Forste, and Lybbert (2018) show that breastfeeding provides a strong foundation for the mother-child bond. Breastfeeding also serves as a social symbol of maternal identity (Marshall, Godfrey, \& Renfrew, 2007; Schmied \& Lupton, 2001; Williams, Kurz, Summers, \& Crabb, 2012). The pressure to provide the best for one's baby, minimize the risk of illness, and meet social expectations is likely to affect the decision to breastfeed (Afflerback, Carter, Koontz, \& Grauerholz, 2013).

While most women who breastfeed do so with babies they have gestated, non-gestating mothers can still choose to breastfeed children who were adopted (Szucs, Axline, \& Rosenman, 2010), born through surrogacy (Banapurmath,
Banapurmath, \& Kesaree, 1993), or born to their female partner (Wilson, Perrin, Fogleman, \& Chetwynd, 2015). For women who have not previously breastfed, this process is

'Department of Public Health, Mental Health and Perinatal Nursing, Faculty of Medicine and Health Sciences, Universitat de Barcelona, L'Hospitalet de Llobregat, Barcelona, Spain

${ }^{2}$ Hospital Universitari Parc Taulí, Sabadell, Barcelona, Spain

${ }^{3}$ Research group on Methodology, Models, Methods and Outcomes of Health and Social Sciences (M3O) Faculty of Health Sciences and Welfare, University of Vic-Central University of Catalonia (UVic-UCC), Vic, Spain

${ }^{4}$ AFIN. Social and Cultural Department, Universitat Autònoma de Barcelona, Bellaterra, Spain

${ }^{5}$ Department of Public Health, Mental Health and Perinatal Nursing, Faculty of Medicine and Health Services, ADHUC-Research Center for Theory, Gender and Sexuality, Universitat de Barcelona, L'Hospitalet de Llobregat, Barcelona, Spain

Date submitted: May I, 20I8; Date accepted: May 4, 2019.

\section{Corresponding Author:}

Paola Galbany-Estragués, Faculty of Health Sciences and Welfare, University of Vic - Central University of Catalonia (UVic-UCC), C. Sagrada Família, 7, Vic, Barcelona 08500, Spain.

Email: paola.galbany@uvic.cat 
called "induced lactation." If they have previously breastfed, it is termed "relactation" (WHO, 1998). Mothers often decide to undergo induced lactation or relactation to strengthen the mother-child bond (Flores-Antón, García-Lara, \& PallásAlonso, 2017).

Induced lactation and relactation have gained popularity in Spain over the past 15 years, as traditional families have given way to new family structures, under which children enter a family via adoption, surrogacy, or sperm donation. Adoption has become very common in Spain, where around 1000 children are adopted each year (Ministerio de Sanidad, Servicios Sociales e Igualdad, 2017a). When it comes to surrogacy, although the practice is illegal in Spain (Techniques of Assisted Human Reproduction Act, 2006), Spanish citizens often arrange surrogate pregnancies in countries where the practice is legal (Darnovsky \& Beeson, 2015). Couples comprising two women can legally use insemination with donor sperm to achieve a pregnancy (Techniques of Assisted Human Reproduction Acts 2006, 2015).

In Spain, according to the most recent national health survey, $74 \%$ of infants aged 6 weeks are fed with human milk. This figure drops to $64 \%$ at 3 months and $39 \%$ at 6 months (Instituto Nacional de Estadística [INE], 2017). The main reasons for cessation of breastfeeding is perceived milk insufficiency and returning to work (Ramiro et al., 2017). There are no data available regarding the prevalence of induced lactation or relactation in Spain.

Much of the existing research about induced lactation and relactation concerns methods. In the pharmacological method, women take galactogogues or hormonal treatments (estrogen and progesterone). Hormonal treatments create a hormonal state similar to that which occurs during pregnancy. Both treatments have potential side effects, including weight gain, headaches, gastric problems, depression, and irregular periods. In addition to taking medication, women using the pharmacological approach must also undergo breast stimulation (Forinash, Yaney, Barnes, \& Myles, 2012; Sabatini \& Cagiano, 2006). Induced lactation and relactation can also be also performed using non-pharmacological methods based on the frequent stimulation of the breasts. Herbal galactogogues (e.g, fenugreek and blessed thistle) are sometimes used to assist in relactation and induced lactation (Wittig \& Spatz, 2008).

Researchers have identified success factors for induced lactation and relactation, including maternal motivation, positive attitude, frequent stimulation of breasts, sucking by the baby, family support (especially the partner's), and support from health professionals (Gribble, 2004). Lommen and Brown (2015) concluded that the support that women received from breastfeeding services and their families enabled them to breastfeed their babies and face feelings of rejection, anger, stress, and failure. Flores-Antón et al. (2017) described a mother who managed to feed her adopted baby exclusively with her own milk and argued that motivation and confidence helped her succeed.

\section{Key Messages}

- The main motivation for undergoing induced lactation or relactation was to strengthen closeness between the mother and child through breastfeeding. Participants reported that breastfeeding cessation diminished this feeling of closeness.

- During the processes of induced lactation and relactation, the key challenges for women were physical difficulties, lack of information, lack of support from professionals, and doubts about whether they would have a successful outcome and be able to breastfeed their babies.

- Women who underwent induced lactation and were therefore breastfeeding for the first time experienced problems with their breasts. Women undergoing relactation did not have problems with their breasts.

As we have outlined, studies about induced lactation and relactation focus on methods and success factors. However, there is a lack of research about the experience of women who undergo these processes, which we divided into three phases: induction/relactation until the establishment of milk production; the breastfeeding of the infant; and breastfeeding cessation. As far as we know, our study was the first in which researchers examined, under a single lens, the three modes of reproduction in which women may choose lactation and relactation (adoption, surrogacy, and sperm donation). Specifically, we describe the challenges faced by women in Spain undergoing induced lactation and relactation. This research is important because new family models in Spain have increased cases of induced lactation and relactation, but little is known about how non-gestating women experience these processes. Our aim in this study was to describe the challenges faced by mothers who undergo induced breastfeeding and relactation for adopted infants, infants born via surrogacy, and infants born to same-sex female partners.

\section{Methods}

\section{Design}

This was a prospective and cross-sectional generic qualitative study. To explore the experiences of women who had undergone induced lactation and relactation, we deemed qualitative methods to be most appropriate, given that they allow researchers to understand participants experiences (Jiggins \& Evans, 2016; Renate, 2014; Sandelowski, 2000). The research was approved by the Research Ethics Committee of the Health Corporation of Parc Taulí Hospital (reference 2015568) and the Bioethics Committee of the University of Barcelona (reference IRB00003099). 


\section{Setting}

The research were based in Catalonia, Spain. Spain has a public health system providing universal, comprehensive, free care to citizens and foreign residents. Pregnancy, childbirth, and postpartum care are fully covered. Spain also has private hospitals offering pregnancy, childbirth, and postpartum care. Breastfeeding is encouraged and supported in both the public and private systems. In both systems, pregnant women receive breastfeeding education and support during pregnancy, immediately after childbirth, and during postpartum visits (Ministerio de Sanidad, Servicios Sociales e Igualdad, 2017b). Outside the health system, women can also receive breastfeeding support privately from lactation support providers and International Board Certified Lactation Consultants.

\section{Sample}

The target population was women living in Spain who had undergone induced lactation or relactation to breastfeed an adopted child, a child born through surrogacy, or a child born to the woman's same-sex partner through sperm donation. We define breastfeeding as the process by which a child consumes human milk (including expressed milk and milk from a wet nurse). The breastfed infant may also consume other food or liquid, including non-human milk and formula (Noel-Weiss, Boersma, \& Kujawa-Myles, 2012). Inclusion criteria were: (1) women who had undergone induced lactation or relactation and were no longer breastfeeding their children; (2) women who, after undergoing induced lactation or relactation, were still breastfeeding; or (3) women who had undergone induced lactation or relactation and who were in the process of ceasing breastfeeding. All women participated voluntarily in the study. Sample exclusion criteria were: $(1)<18$ years of age at the time of the study; (2) women who did not speak Spanish or Catalan; and (3) women outside Catalonia who were unable to perform the interview via videoconference. Participants were not required to have undergone induction or relactation within a certain timeframe.

Author 1 contacted breastfeeding support groups and lactation support providers to identify the first participant. The remaining participants were identified with snowball sampling. Ten women were identified, and nine of these met the inclusion criteria. We contacted these nine women via email to offer study details, provide a consent form guaranteeing data confidentiality, and to commit to informing participants of the study results. The sample was small due to the small population size and the difficulty of recruitment. We were able to recruit three participants each from the three situations in which induced lactation and relactation occur. We ceased recruiting participants when we reached data saturation.

\section{Data Collection}

All participants gave their consent before being interviewed. All data were collected between October 2014 and May 2017. The lengthy timeframe for data collection resulted from our difficulties in recruiting participants. Few women in Spain choose induction or relactation in the case of adoption, surrogacy, or a partner's pregnancy. Moreover, there is no database tracking the existing cases.

Semi-structured interviews were conducted using openended questions that addressed difficulties during the process, motivational and de-motivational factors, feelings and thoughts, and an evaluation of the entire process (Kallio, Pietilä, Johson, \& Kangasniemi, 2016). We organized the interview guide (Table 1) around the three phrases of induction and relactation, and we developed the interview questions following classic studies in which researchers have laid the groundwork for understanding the experiences of women undergoing these processes (Auerbach \& Avery, 1981; Hormann, 1977; Thearle \& Weissenberger, 1984). This kind of deductive design is useful in ensuring that all areas the researchers wish to investigate emerge in the interviews (Percy, Kostere, \& Kostere, 2015). Author 1 conducted in-person interviews with five participants and Skype interviews with four. Interviews were conducted in Catalan and/or Spanish and averaged 50 min (range $=40$ 160). They were recorded and transcribed in the original language and checked by Authors 1 and 2. A professional translator translated the examples from the original language into English.

To maximize the reflexivity of the research process (Buetow, 2019; Dogson, 2019), Author 1 kept a field diary in which she reported her impressions of each interview. In the interviews, she presented herself to study participants as a nurse-midwife and a student undertaking a $\mathrm{PhD}$ in nursing. Participants' awareness that Author 1 was a nurse-midwife may have led them to paint an overly positive picture of breastfeeding. However, their multiple descriptions of the difficulties they faced seems to discourage this interpretation.

Participants' names were substituted with the letter "P" (participant), followed by a number. Author 1 saved the transcribed interviews on a personal hard drive to maintain participants' confidentiality. Once the study is completed and published, transcripts will be destroyed.

\section{Data Analysis}

The analysis process is detailed in Table 2. Following Braun and Clarke (2006), we familiarized ourselves with the data, generating an initial set of codes that drew on the theoretical model and our interview guide. Then Authors 1 and 2 jointly read and coded the transcriptions using ATLAS.ti v.7.5.7 (Scientific Software Development GmbH, 2015). We then incorporated the emerging codes into our predetermined 
Table I. Interview Guide.

Stages of the Process of Induced Lactation / Relactation

I. Induced lactation / relactation

2. Establishment of breastfeeding

3. Breastfeeding cessation

4. Entire process
Questions

What difficulties or unpleasant aspects appeared during the process of induced lactation or relactation? (Difficulties during the process, motivational and de-motivational factors)

What was your relationship with the health professionals during induced lactation or relactation? (Feelings and thoughts)

What aspects would you have liked to have covered with the health professionals? Were you unable to discuss any of these with them? Why? (Difficulties during the process)

Did you have any problems during the process? (Difficulties during the process)

Did you feel supported during the process? Who provided you with the greatest support? (Feelings and thoughts, motivational and de-motivational factors)

Did you experience any problems with your breasts during breastfeeding? (Difficulties during breastfeeding)

How was your experience breastfeeding? (Feelings and thoughts, motivational and demotivational factors)

Did you experience any problem during breastfeeding cessation? (Difficulties during breastfeeding cessation)

How was your relationship with your child during breastfeeding cessation? (Feelings and thoughts)

What would you say was your overall experience of this entire process? (Feelings and thoughts / difficulties during the process / motivational and de-motivational factors)

Table 2. Analysis Process.

\begin{tabular}{ll}
\hline Stage & \multicolumn{1}{c}{ Description of the process } \\
\hline Creation of categories & $\begin{array}{c}\text { Creation of categories from the semi-structured interview questions, which were } \\
\text { devised on the basis of previous literature on induction and relactation } \\
\text { Transcription of the interviews and reading of the transcribed data } \\
\text { Grouping the quotes that repeat themselves in patterned ways, to create codes }\end{array}$ \\
$\begin{array}{l}\text { Immersion in the data } \\
\text { Initial generation of codes }\end{array}$ & $\begin{array}{l}\text { Grouping the interrelated codes under the pre-established categories } \\
\text { Re-reading of the data to confirm that the categories are correct }\end{array}$ \\
Confirmation of categories & Determining the definitive categories \\
Definitive categories & Final report with the definitive categories and codes \\
Final report &
\end{tabular}

categories (Table 3). We conducted team meetings to compare and contrast our interpretations of the data and to identify relationships among codes and categories (Dogson, 2019).

\section{Results}

The average age of the participants when undergoing induced lactation or relactation was 33 years (standard deviation $[S D]: 3.87)$. The average age of the infants at the start of breastfeeding was 17 days (SD: 28.92) and the average length of breastfeeding was 17 months ( $S D$ : 17.06). In all cases, it was the first time that the participant underwent a process of induced lactation or relactation. Seven participants breastfed a single child, while two breastfed twins. Table 4 shows the demographic characteristics of the participants.

We organized our data into three categories: challenges of induced lactation or relactation; challenges of breastfeeding; and challenges of breastfeeding cessation.

\section{Challenges of Induced Lactation or Relactation}

Physical Challenges. Seven (78\%) of the participants underwent the process of relactation or induced lactation before their child arrived. The remaining two (22\%) participants, P-2 and P-3, began the process after the child arrived. The process of induced lactation or relactation required roundthe-clock stimulation of the breasts, which often caused stress to participants. All participants reported that it was worth undergoing induced lactation or relactation to be able to breastfeed their children.

The stress that it can cause you at the beginning with your partner, with your family, and imposing those routines, because it is quite a tedious routine, every 2 or 3 hours and at night, whatever we do, having to go to the bathroom to pump milk, and touch my breasts for 10 minutes. (P-2)

The process not only affected their relationship with their partners but also their colleagues: "The most difficult was at work, 
Table 3. Categories, Definitions of Categories, Codes, and Definitions of Codes.

\begin{tabular}{|c|c|c|c|}
\hline Category & Definition of Category & Code & Definition of Code \\
\hline \multirow[t]{3}{*}{$\begin{array}{l}\text { Challenges During } \\
\text { Induction of Lactation or } \\
\text { Relactation }\end{array}$} & \multirow{3}{*}{$\begin{array}{l}\text { The participants experienced } \\
\text { challenges during the period } \\
\text { of induction of lactation or } \\
\text { relactation, until they were } \\
\text { able to produce milk }\end{array}$} & $\begin{array}{l}\text { I. Hardship during the process of } \\
\text { inducing lactation or relactation }\end{array}$ & $\begin{array}{l}\text { I. Routines, disciplines, stimulation both } \\
\text { during the day and night, secondary } \\
\text { effects of medication, stress }\end{array}$ \\
\hline & & $\begin{array}{l}\text { 2. Difficulty obtaining information } \\
\text { from health professionals } \\
\text { (midwifes, RNs, and physicians) }\end{array}$ & $\begin{array}{l}\text { 2. No access to information, inappropriate } \\
\text { information, lack of information }\end{array}$ \\
\hline & & $\begin{array}{l}\text { 3. Doubts and fears during the } \\
\text { process of inducing lactation or } \\
\text { relactation }\end{array}$ & $\begin{array}{l}\text { 3. Not being able to produce milk, } \\
\text { insufficient milk supply }\end{array}$ \\
\hline \multirow[t]{2}{*}{$\begin{array}{l}\text { Challenges During } \\
\text { Breastfeeding }\end{array}$} & \multirow{2}{*}{$\begin{array}{l}\text { The participants experienced } \\
\text { challenges during } \\
\text { the establishment of } \\
\text { breastfeeding and the period } \\
\text { of breastfeeding itself }\end{array}$} & 4. Problems with the breast & $\begin{array}{l}\text { 4. Cracked nipples, nipple blebs, blocked } \\
\text { ducts, pain, suction problems }\end{array}$ \\
\hline & & $\begin{array}{l}\text { 5. Doubts about whether the } \\
\text { amount of milk supplied was } \\
\text { sufficient }\end{array}$ & $\begin{array}{l}\text { 5. Insufficient milk supply for feeding the } \\
\text { baby }\end{array}$ \\
\hline \multirow[t]{2}{*}{$\begin{array}{l}\text { Difficulties During } \\
\text { Breastfeeding Cessation }\end{array}$} & \multirow[t]{2}{*}{$\begin{array}{l}\text { The participants experienced } \\
\text { challenges during } \\
\text { breastfeeding cessation }\end{array}$} & $\begin{array}{l}\text { 6. The end of shared } \\
\text { responsibility for breastfeeding } \\
\text { with the partner }\end{array}$ & $\begin{array}{l}\text { 6. In the case of couples comprising two } \\
\text { women, the induced or relactating } \\
\text { mother ceased breastfeeding before her } \\
\text { partner }\end{array}$ \\
\hline & & 7. Reduced feeling of closeness & $\begin{array}{l}\text { 7. The end of breastfeeding diminished the } \\
\text { mother's sense of closeness to the child }\end{array}$ \\
\hline
\end{tabular}

Table 4. Demographic Characteristics of the Participants $(N=9)$

\begin{tabular}{|c|c|c|c|c|c|c|c|c|c|}
\hline ID & $\begin{array}{c}\text { Maternal } \\
\text { Age (years) }\end{array}$ & $\begin{array}{l}\text { Maternity } \\
\text { without } \\
\text { Pregnancy }\end{array}$ & Prior Pregnancy & $\begin{array}{l}\text { Prior } \\
\text { BF }\end{array}$ & $\begin{array}{l}\text { Induction/ } \\
\text { relactation } \\
\text { Method }\end{array}$ & $\begin{array}{l}\text { Type } \\
\text { of BF }\end{array}$ & $\begin{array}{c}\text { BF } \\
\text { Support }\end{array}$ & $\begin{array}{l}\text { Child's age at } \\
\text { start of BF }\end{array}$ & $\begin{array}{c}\text { Child's age } \\
\text { at BF } \\
\text { cessation }\end{array}$ \\
\hline I & 29 & Adoption & Full term & Yes & $\mathrm{H}, \mathrm{HG}, \mathrm{S}$ & Mixed & None & 12 weeks & 13 months \\
\hline 2 & 36 & Partner's Pregnancy & No & No & HG, S, SNS & $\mathrm{EBF}$ & $\mathrm{RN}$ & 6 weeks & 7 months \\
\hline 3 & 38 & Adoption & Full term & Yes & HG, S, SNS & Mixed & IBCLC & 8 days & 4 years \\
\hline 4 & 36 & Adoption & $\begin{array}{l}\text { Miscarriage } \\
\text { 2nd trimester }\end{array}$ & No & $\mathrm{HG}, \mathrm{S}$ & EBF & $\begin{array}{l}\text { RN } \\
\text { IBCLC }\end{array}$ & 4 days & 4 years \\
\hline 5 & 37 & Surrogacy & None & No & $\mathrm{H}, \mathrm{HG}, \mathrm{S}$ & Mixed & Physician & From birth & 6 months \\
\hline 6 & 30 & Partner's Pregnancy & None & No & $\mathrm{H}, \mathrm{HG}, \mathrm{S}$ & $\mathrm{EBF}$ & $\begin{array}{l}\text { Midwife } \\
\text { IBCLC }\end{array}$ & From birth & 15 months \\
\hline 7 & 28 & Partner's Pregnancy & None & No & $\mathrm{H}, \mathrm{HG}, \mathrm{S}$ & Mixed & $\begin{array}{l}\text { Midwife } \\
\text { LSP }\end{array}$ & From birth & 4 months \\
\hline 8 & 32 & Surrogacy & None & No & $\mathrm{H}, \mathrm{HG}, \mathrm{S}$ & Mixed & None & From birth & 10 months \\
\hline 9 & 38 & Surrogacy & $\begin{array}{l}\text { Miscarriage Ist } \\
\text { trimester }\end{array}$ & No & $\mathrm{H}, \mathrm{HG}, \mathrm{S}$ & Mixed & IBCLC & I months & 1.5 months \\
\hline
\end{tabular}

Note. Abbreviations: $\mathrm{BF}=$ breastfeeding; $\mathrm{EBF}=$ exclusive breastfeeding; $\mathrm{H}=$ hormonal; $\mathrm{HG}=$ herbal galactogogues; IBCLC $=$ International Board Certified Lactation Consultant; LSP = lactation support provider; mixed feeding = BF and formula; $\mathrm{S}=$ stimulation; SNS = supplemental nursing system, registered nurse (RN).

aMaternal age at time of induction or relactation.

disappearing for 10, 15 minutes. It was very strange [to my colleagues] for me to disappear" (P-7). For P-2 and P-8, on medication during the process, side effects during hormonal treatments and galatogogues included weight gain, headaches, and decreased sexual desire. These participants did not interpret these symptoms negatively: "I gained a few sizes due to the medication, however, truthfully, I did not mind" (P-2). "The medication gave me a headache and very low sexual desire. But I knew why so I could live with it" (P-8).
Lack of Information From Health Professionals. Only P-5, who became a mother by surrogacy in 1999, said she felt satisfied with the support of her physicians during the process of inducing lactation. The other participants felt that the information and support provided by their midwives, nurses, and physicians was inadequate, which made them turn to the Internet: "I remember the phrase [from my family doctor]: 'You will not be able to breastfeed, not even an ant"" $(\mathrm{P}-1)$. 
The pediatrician came and told us that I should not breastfeed the baby, that the mother who gave birth to him should. She said that the baby was unwell and that she did not know if the quality of my milk was good. (P-7)

"I have often met mothers wondering: 'Could I have done this?' And I respond: 'Yes, of course, if someone had told you!"” (P-1). "They [the health professionals] could have taken an interest and guided me" (P-3). Some participants, like P-2, felt that health professionals should be more informed about modern family structures and the possibility of induced lactation or relactation for babies raised by two women: "Is there anything missing? Well, that would be more training for health professionals about couples so they know that this is possible, positive, and that both of you can do it" (P-2).

Lack of Support From Close Family Members and Friends. Primary support came from participants' partners. All admitted to being questioned about their decision by their family and close friends: "At first, it is like: 'What is she doing?' And that is tough, at least in my case it was" (P-3). Participants admitted feeling questioned for undergoing induced lactation or relactation and about the quantity and quality of their milk: "Many people, friends, told me: 'Do you know that you are going to be a mother anyway, even if you do not breastfeed?' They felt it was a major complication" (P-9). "Later, when I produced milk they said: 'Ok, but is that milk real? Will it be of any use to the baby?"' (P-4). P-2, P-6, and $\mathrm{P}-7$, participants who underwent induced lactation or relactation to breastfeed a child born by their female partner felt judged not only for wanting to be mothers, but also for wanting to breastfeed their babies.

Doubts About the Outcome. All participants experienced doubts about whether they would be able to induce lactation or relactation successfully. These doubts were due to the slow pace of inducing lactation and relactation, the long waiting period before results emerged, the fact that milk production sometimes plateaued, and their frustration during the process. "I saw that you came to a point at which it [the milk] did not increase any more, and it made me think: 'Oh my goodness, will that be enough?'" (P-1). They also feared that their babies would have difficulty breastfeeding or might reject the breast.

I did not know if all this effort was going to be worth it. At first, you feel full of hope, see if this will work, when you see it does, you get very excited, when you see that you really have milk. But it is also frustrating because I was scared my baby might not want it. (P-2)

Some participants linked the stress that they experienced while expecting a child to their own doubts about the success of the process as expressed by P-1, an adoptive mother: "The chances of succeeding already are not great ... and in a process like adoption, which is really long, maybe you are not at your best" (P-1).

\section{Challenges During Breastfeeding}

Problems with Breast Health. P-1 and P-3 had had prior breastfeeding experience and did not experience any problems with their breasts during breastfeeding after relactation. However, the remaining participants, who had not breastfed before, reported problems including cracked nipples (P-6, P-9); nipple blebs or milk blisters (P-4, P-9); stiffened areas of the breast due to stimulation (P-2); the baby having problems with sucking (P-5); the baby having difficulty in latching on to the participant's breast, but not to the gestating mother's breast (P-7); and blocked ducts (P-8). These problems appeared during the first month of breastfeeding and were mostly resolved during the first month and a half, except for P-8, who, when back at work, again experienced blocked ducts, and P-7, who reported that her baby had difficulty latching on for the entire 4-month period of breastfeeding. To solve sucking problems, P-5's registered nurse taught her exercises to stimulate sucking. For P-4's nipple blebs and P-6's cracked nipples, lactation support providers taught them to perform postural changes when breastfeeding to drain all areas of the breast. One of P-6's twins required a frenotomy to correct a tongue-tie.

Doubts About Milk Supply. Participants reported doubts about whether their induced milk supply would be enough for their babies. Participants who had previously breastfed (P-1, P-3) acknowledged having more doubts about breastfeeding after relactation compared to previous experiences:

Considering that the baby was smaller, and that it was not breastfeeding immediately after birth, there was a doubt that the baby would have enough [milk], you know? I had that doubt, you know? More doubts. (P-1)

\section{Challenges During Breastfeeding Cessation}

The end of Shared Breastfeeding Responsibility With the Partner. P-2 and p-6 had shared breastfeeding with their female partners who had given birth to their babies. When these participants ceased breastfeeding, their partners continued breastfeeding. This change caused stress in the couples and shifted their responsibilities in caring for their children. P-6's partner went from feeding one of their babies to feeding both: "Sharing the burden is the least romantic part, but it is true that I also felt motivated to continue supporting my partner, because it was very tiring with the two of them" (P-6). Except for P-2, who decided to stop breastfeeding for personal reasons, all participants stopped breastfeeding because of the baby's disinterest in breastfeeding. The babies asked 
to nurse less often, and the babies who received formula supplements (P-7 and P-9) preferred the bottle to the breast.

Reduced Closeness. P-4 and P-7 were still breastfeeding at the time of their interviews, while the other participants had already ceased breastfeeding or were in the process of doing so. All participants saw the end of breastfeeding as a loss and linked it to a decrease in the closeness between mother and child. This aspect made breastfeeding cessation particularly difficult for the participants, since the desire for closeness was the main reason they had undergone induced lactation or relactation in the first place. An example is P-2, whose female partner was still breastfeeding their child, even though P-2 herself had weaned:

There is a change, in the sense that no, they do not seek you out in the same way; there is not the dependency now that the child has with my partner, when it was more shared-and yes, it changes. For me, it changes. (P-2)

\section{Discussion}

Our study participants faced the same challenges, regardless of the mode of reproduction. The greatest challenge of induced lactation or relactation was physical. As also reflected in previous studies, the process required an effort that could be stressful but that was rewarded when the mother was able to breastfeed her baby (Da Rocha, Meneses, \& Nazareth, 2014). The most difficult part of the process for our participants was the round-the-clock stimulation of the breasts (Shiva, Frotan, Arabipoor, \& Mirzaaga, 2010). It should be pointed out, however, that induced lactation and relactation can also be achieved after the baby arrives by putting the baby to the breast (Abejide et al., 1997). This option should be kept in mind as a way of avoiding the onerous process that our study participants went through, and thus reducing stress.

Because of the physical difficulty of the process, external support is essential, and our participants expected that health professionals would provide relevant information and support. Other researchers have shown that health professionals often do little to promote induced lactation or relactation because they are unfamiliar with these processes (Da Rocha et al., 2014; Saari \& Farahwahida, 2014). When our participants failed to receive professional support, they obtained additional information via the Internet, a strategy that, without supervision from a health professional, may lead to inappropriate conclusions (Hartzband \& Groopman, 2015). While participants found that professional support was lacking, they reported receiving emotional support from their partners, which increased their willpower and sense of security, and assisted them through the challenges of the process. While participants reported good support from their partners, they agreed that they received very little support from friends, compared to women who breastfeed children to whom they have given birth. We agree with Lommen and Brown (2015) that more support and a positive outlook would help encourage breastfeeding in non-gestating mothers.

The challenges of breastfeeding itself that our study participants faced were similar to those reported for gestating mothers: breast health and milk supply (Barbosa et al., 2017). Like previous researchers (Hackman, Schaefer, Beiler, Rose, $\&$ Paul, 2015), we show that participants who were breastfeeding for the first time often had more difficulty initiating breastfeeding than those who had breastfed previously. With respect to their doubts about milk supply, similar to other findings (Da Rocha et al., 2014; Saari \& Farahwahida, 2014; Shiva et al., 2010), the type of feeding (i.e., exclusive breastfeeding, predominant breastfeeding, mixed feeding or bottle feeding), and the inability to exclusively breastfeed a child, did not negatively affect the participants. This finding coincides with their belief that the benefit to the mother-child relationship was significant regardless of how much milk was produced.

Finally, the participants agreed that their feeling of closeness with their child had been strengthened by breastfeeding and that this closeness weakened when they ceased breastfeeding. Although returning to work is often related to breastfeeding cessation (Li, Fein, Chen, \& Grummer-Strawn, 2008), this factor did not affect participants in our study because they were all able to reduce their working hours or lengthen their leave.

Participants' motivation for breastfeeding was to improve their sense of closeness to their infants, and they reported that their expectations had been fulfilled. In future studies, researchers should compare sense of closeness to one's infant between non-gestating mothers who breastfeed their infants and those who do not.

\section{Limitations}

We included two study participants who were still breastfeeding and therefore who had not gone through the phase of breastfeeding cessation; as a result, our sample for this phase was limited to seven participants. Overall, the small size of our sample limits our ability to making definitive claims or generalize our results to other settings. The sample may appear to be skewed toward women with a high educational level. However, this characteristic is probably general to women who choose induced relactation or relactation, and therefore not a sampling error. Our use of snowball sampling may have skewed the sample toward women who were similar to each other. Finally, the authors' own positioning as nurses and nurse-midwivesand therefore recognizable as people in favor of breastfeeding - could have affected the participants' responses and the researchers' interpretations. 


\section{Conclusion}

At a time when people use a range of modes of reproduction to create their families, health professionals need to know about induced lactation and relactation in order to provide proper guidance and assistance. Researchers and practitioners can use our study to better understand the lived experiences of women during induced lactation and relactation, and health professionals and lactation support providers can draw on it when they offer care during these processes.

\section{Acknowledgments}

The authors thank all women who have shared their experiences and have allowed the realization of this study. Furthermore, we would like to thank Dr Clara Juandó Prats for her research support, and Dr Susan Frekko, who translated the article from Spanish to English and provided feedback on several versions.

\section{Declaration of Conflicting Interests}

The authors declared no potential conflicts of interest with respect to the research, authorship, and/or publication of this article.

\section{Funding}

The authors received no financial support for the research, authorship, and/or publication of this article.

\section{ORCID iDs}

Gemma Cazorla-Ortiz iD https://orcid.org/0000-0002-2560-6856 Paola Galbany-Estragués iD https://orcid.org/0000-0003-3775-1695 Josefina Goberna-Tricas iD https://orcid.org/0000-0002-3531-9009

\section{References}

Abejide, O. R., Tadese, M. A., Babajide, D. E., Torimiro, S. E., Davies-Adetugbo, A. A., \& Makanjuola, R. O. (1997). Nonpuerperal induced lactation in a Nigerian community: Case reports. Annals of Tropical Paediatrics, 17(2), 109-114.

Afflerback, S., Carter, S. K., Koontz, A., \& Grauerholz, L. (2013). Infant-feeding consumerism in the age of intensive mothering and risk society. Journal of Consumer Culture, 13, 387-405.

Auerbach, K. G., \& Avery, J. L. (1981). Induced lactation: A study of adoptive nursing by 240 women. American Journal of Diseases of Children, 135(4), 340-343.

Banapurmath, C. R., Banapurmath, S., \& Kesaree, N. (1993). Successfully induced non-puerperal lactation in surrogate mothers. The Indian Journal of Pediatrics, 60(5), 639-643.

Barbosa, G. E., Silva, V. B., Pereira, J. M., Soares, M. S., Medeiros, R. D., Pereira, L. B., Pinho, L., \& Caldeira, A. P. (2017). Initial breastfeeding difficulties and association with breast disorders among postpartum women. Revista Paulista de Pediatria, 35(3), 265-272.

Braun, V., \& Clarke, V. (2006). Using thematic analysis in psychology. Qualitative Research in Psychology, 3(2), 77-101.

Buetow, S. (2019). Apophenia, unconscious bias and reflexivity in nursing qualitative research. International Journal of Nursing Studies, 89, 8-13.
Da Rocha, S., Meneses, I. M., \& Nazareth, I. V. (2014). Narratives of lives of women who breastfed their adoptive children. Revista Rene, 15(2), 249-256.

Darnovsky, M., \& Beeson, D. (2015). Prácticas globales de subrogación. Newsletter AFIN, 77, 1-18.

Dodgson, J. E. (2019). Reflexivity in Qualitative Research. Journal of Human Lactation, 35(2), 220-222. doi:10.1177 /0890334419830990

Flores-Antón, B., García-Lara, N. R., \& Pallás-Alonso, C. R. (2017). An Adoptive mother who became a human milk donor. Journal of Human Lactation, 33(2), 419-421. doi:10.1177/0890334416682007

Forinash, A. B., Yancey, A. M., Barnes, K. N., \& Myles, T. D. (2012). The use of galactogogues in the breastfeeding mother. Annals of Pharmacotherapy, 46(10), 1392-1404.

Gibbs, B. G., Forste, R., \& Lybbert, E. (2018). Breastfeeding, parenting, and infant attachment behaviors. Maternal and Child Health Journal, 22(4), 579-588.

Gribble, K. D. (2004). The influence of context on the success of adoptive breastfeeding: Developing countries and the west. Breastfeeding Review, 12(1), 5-13.

Hackman, N. M., Schaefer, E. W., Beiler, J. S., Rose, C. M., \& Paul, I. M. (2015). Breastfeeding outcome comparison by parity. Breastfeeding Medicine, 10(3), 156-162.

Hartzband, P., \& Groopman, J. (2015). Untangling the Web: Patients, doctors, and the internet. The New England Journal of Medicine, 362(12), 1063-1066.

Hormann, E. (1977). Breast feeding the adopted baby. Birth and the Family Journal, 4(4), 165-173.

Instituto Nacional de Estadística. (2017). Encuesta Nacional de Salud. Retrieved from http://www.ine.es/ss/Satellite?L=es ES\&c $=$ INESeccion_C\&cid $=1259926457058 \& p=1254735110$ 672\&pagename $=$ ProductosYServicios\%2FPYSLayout\&para $\mathrm{m} 1=$ PYSDetalle\&param3=1259924822888

Jiggins, K., \& Evans, B. (2016). Qualitative descriptive methods in health science research. Health Environments Research and Design Journal, 9(4), 16-25.

Kallio, H., Pietilä, A. M., Johnson, M., \& Kangasniemi, M. (2016). Systematic methodological review: Developing a framework for a qualitative semi-structured interview guide. Journal of Advanced Nursing, 72(12), 2954-2965.

Law No. 40. Law about Techniques of assisted human reproductive. Boletín Oficial del Estado No. 126, 27th May of 2006. Spain. Retrieved from https://www.boe.es/buscar/act.php?id=BOEA-2006-9292

Li, R., Fein, S. B., Chen, J., \& Grummer-Strawn, L. M. (2008). Why mothers stop breastfeeding: Mothers' self-reported reasons for stopping during the first year. Pediatrics, 122(2), $569-575$.

Lommen, A., \& Brown, B. (2015). Experiential perceptions of relactation: A phenomenological study. Journal of Human Lactation, 31(3), 498-503.

Marshall, J. L., Godfrey, M., \& Renfrew, M. J. (2007). Being a "good mother": Managing breastfeeding and merging identities. Social Science and Medicine, 65, 2147-2159.

Ministerio de Sanidad, Servicios Sociales e Igualdad. (2017a). Boletín de datos estadísticos de medidas de protección a la infancia: Boletín número 18 [Bulletin of statistical data on 
child protection measures: Bulletin number 18]. Retrieved from http://www.msc.es/ssi/familiasInfancia/Infancia/pdf/ Boletinproteccionalainfancia18accesible.pdf

Ministerio de Sanidad, Servicios Sociales e Igualdad. (2017b). Informe Anual del Sistema Nacional de Salud 2017 [Annual Report of the National Health System 2017]. Retrieved from https://www.mscbs.gob.es/estadEstudios/estadisticas/ sisInfSanSNS/tablasEstadisticas/InfAnSNS.htm

Noel-Weiss, S., Boersma, L., \& Kujawa-Myles, S. (2012). Questioning current definitions for breastfeeding research. International Breastfeeding Journal, 7(9), 1-4.

Percy, W. H., Kostere, K., \& Kostere, S. (2015). Generic Qualitative Research in Psychology. The Qualitative Report, 20(2), 76-85.

Ramiro, M. D., Ortíz, H., Arana, C., Esparza, M. J., Cortés, O., Terol, M, \& Ordobás, M. (2017). Prevalence of breastfeeding and factors associated with the start and duration of exclusive breastfeeding in the Community of Madrid among participants in the ELOIN. Anales de Pediatría, 89(1), 32-43.

Renate, M. K. (2014). Generic qualitative approaches: Pitfalls and benefits of methodological mixology. International Journal of Qualitative Methods, 13, 37-52.

Saari, Z., \& Farahwahida, Y. (2014). Induced lactation by adoptive mothers: A case study. Jurnal Teknologi, 68(1), 123-132.

Sabatini, R., \& Cagiano, R. (2006). Comparison profiles of cycle control, side effects and sexual satisfaction of three hormonal contraceptives. Contraception, 74(3), 220-223.

Sandelowski, M. (2000). Whatever happened to qualitative description? Research in Nursing \& Health, 23, 334-340.
Schmied, V., \& Lupton, D. (2001). Blurring the boundaries: Breastfeeding and maternal subjectivity. Sociology Health Illness Journal, 23(2), 234-250.

Scientific Software Development GmbH. (2015). Atlas ti Qualitative Data Analysis (Version 7.5.7). [Computer software]. Retrieved from http://www.atlasti.com

Shiva, M., Frotan, M., Arabipoor, A., \& Mirzaaga, E. (2010). A successful induction of lactation in surrogate pregnancy with metoclopramide and review of lactation induction. International Journal of Fertility and Sterility, 3(4), 191-194.

Szucs, K., Axline, S. E., \& Rosenman, M. B. (2010). Induced lactation and exclusive breast milk feeding of adopted premature twins. Journal of Human Lactation, 26, 309-313.

Thearle, M. J., \& Weissenberger, R. (1984). Induced lactation in adoptive mothers. Journal of Obstetrics and Gynaecology, 24, 283-286.

Williams, K., Kurz, T., Summers, M., \& Crabb, S. (2012). Discursive constructions of infant feeding: The dilemma of mothers' guilt. Feminism \& Psychology, 23(3), 339-358.

Wilson, E., Perrin, M. T., Fogleman, A., \& Chetwynd, E. (2015). The intricacies of induced lactation for same-sex mothers of an adopted child. Journal of Human Lactation, 31(1), 64-67.

Wittig, L. S., \& Spatz, L. D. (2008). Induced lactation. Gaining a better understanding. MCN, The American Journal of Maternal/Child Nursing, 33(2), 76-81.

World Health Organization. (1998). Relactation: Review of experience and recommendations for practice. Retrieved from: http://www.who.int/maternal_child_adolescent/documents/ who_chs_cah_98_14/en/

World Health Organization (2017). 10 facts on breastfeeding. Retrieved from http://www.who.int/features/factfiles/breastfeeding/es/ 